\title{
Scrooge
}

Shaun Sellars continues this series on ethical dilemmas in dentistry which appears in every second issue of the $B D J$.

At this time of year, we tend to look forward to what the future holds. Perhaps even more so this year given the challenges that 2020 has provided. Finally, there appears to be a glimmer of light at the end of the tunnel. Several vaccinations against COVID19 are due to be released imminently. They may already be in circulation as you read this, and for many of us, thoughts turn to the future of dentistry.

COVID-19 has undoubtedly had a devastating effect on dentistry and allied professions, but it also provides an opportunity to reset our ideas of what dentistry should be. With contract reform on the horizon, the age-old question of what dentistry should be returns like a bad penny.

Talk often centres on the idea of a core NHS service, providing essential dentistry to as many people as possible. Theoretically, this means that dentists can focus on being healthcare providers while reducing costs incurred to the state. But there are a significant number of practitioners that seem not to want to focus on the healthcare side of dentistry, and more worryingly, there are young people entering dentistry whose main aim is to be a 'private' or 'cosmetic' dentist.

Of course, experienced practitioners wanting to provide cosmetic, elective treatment to patients is routine. There will always be a market for such treatment, and people who seek cosmetic dentistry are deserving of care. But, without wanting to sound too 'bah-humbug', for trainee dentists to be already focusing on providing advanced cosmetic dentistry is problematic. Dentistry is, and forever should be, first and foremost, healthcare. By its very

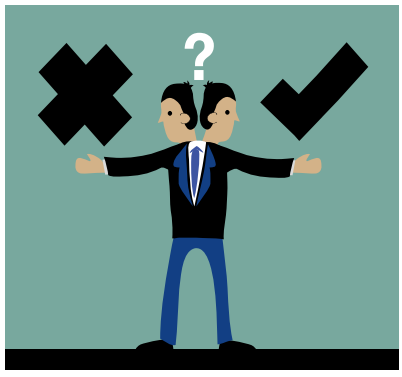
nature, there will always be an aesthetic component to dentistry, but concentrating solely on this outcome is to do a disservice to patients.

How has it come to this? Undoubtedly social media and associated influencers have a role to play. Becoming 'Instagram famous' now seems a valid part of many a dentist's career pathway. People sell courses and books on how to use social media to your business advantage. Is this what we want dentistry to become in the future? Do we want patients to judge us based on how well we edit our clinical photos and how many posts we have with bright white smiles?

Our best advertisement has traditionally been by word of mouth, and despite what the marketers tell you, this will continue for the foreseeable future. Rather than focusing on what hashtag to use on our social media posts, maybe we should be thinking about complementing our clinical skills with non-clinical skills. How we connect with the patient in the chair is what those patients care about, and it's what they're able to judge.

It's not that long ago that the only advertising we were allowed was the brass plaque outside the practice. Anything else was considered too commercial. Too vulgar. That ghost of dentistry past has faded into history. We have moved with the times, and rightly so, but the future of dentistry doesn't need an Instagram filter applied to it. It needs communication.

\section{GDC updates Brexit information for new registrants}

The General Dental Council (GDC) has updated its Brexitrelated information for dental professionals. The transition period for the UK formally leaving the European Union comes to an end on 31 December 2020.

EEA-qualified dentists already registered with the GDC will continue to be registered to practise; no further action is required. For EEA-qualified dentists who submit a GDC registration application before $11 \mathrm{pm}$ on 31 December 2020, the application will be completed under the process that was in effect on the date it was received.

For EEA-qualified dentists applying for GDC registration from $11 \mathrm{pm}$ on 31 December 2020, the UK government has enacted legislation which enables the GDC to continue recognising EEAqualified dentists under a near-automatic system for up to two years from 1 January 2021.

For full details and further information visit: https:// www.gdc-uk.org/registration/join-the-register/ brexit-information-for-dental-professionals.

\section{New President for BSDHT}

The British Society of Dental Hygiene and Therapy (BSDHT) has announced that Diane Rochford is the new

President of the Society.

Diane has proven herself to be a real asset to the Society during the last few years - not only steadfastly upholding its values but also joining in with its spirit of innovation and joining the campaign for change.

Previously, Diane held the position of Elected Council Member and acted as representative of the North West Regional group. Diane has also always been on the educational panel for the Society and has published many articles in the field.

Retiring President Julie Deverick has held the position for two years. The BSDHT thanked her and said: 'Julie has been fearless in promoting the voices of dental hygienists and dental therapists across the nation, not only by campaigning for change in the industry but also by offering a supportive shoulder for all those in need'. 